\title{
Construction of Tissue-Engineered Venous Valves in Vitro Using Two Types of Progenitor Cells and Decellularized Scaffolds Category: Original Article
}

\author{
Yu Wen ${ }^{\dagger}$, Jian-Ming Yuan ${ }^{\dagger}$, Rui-Shan Dang, Xiang-Qun Yang, Shao-Hu Xiong, Man-Ru Shen, \\ Yong-Zhen Zhang and Chuan-Sen Zhang ${ }^{*}$
}

Institute of Biomedical Engineering, Second Military Medical University (SMMU), Shanghai, P.R. China

\begin{abstract}
Objective: To construct tissue-engineered (TE) venous valves in vitro using two types of bone marrow-derived progenitor cells and decellularized scaffold. Methods: Bone marrow-derived multipotent adult progenitor cells (MAPC) and endothelial progenitor cells (EPC) from canines were labeled by Hoechst or PKH26, respectively. And they were both implanted into an allograft acellular vein containing a valve to construct a tissue-engineered venous valve in vitro by culturing in the medium. Growth and migration of MAPC and EPC in the scaffold and inner surface were observed via cryosectioning. The cells distribution, differentiation and endothelium in the scaffold material were assessed by HE staining and immunohistochemical staining. Result: MAPC grew, migrated, and differentiated into smooth muscle-like cells in the scaffold material. EPC grew, migrated, and differentiated into the endothelial cells; and they completely endothelialized the inner surface of the vascular and both sides of the venous valves. Conclusion: We successfully constructed tissue-engineered vein valves using two types of bone marrow-derived progenitor cells and decellularized scaffold in vitro.
\end{abstract}

Keywords: Multipotent adult progenitor cells, endothelial progenitor cells, acellularized scaffold, tissue-engineered, vein valve reconstruction.

\section{INTRODUCTION}

Chronic venous insufficiency, mostly caused by deep venous-valve incompetence, is a common peripheral vascular disease with considerable prevalence worldwide [1]. Followed by the development of venous insufficiency, varicose veins lead to skin changes and ulcers that negatively impact the quality of life of these patients [2]. Although the injured venous valve can be repaired and replaced by autologous vein containing valve [3], the high recurrence rate and limited sources of autologous valves is still puzzling clinicians.

The past decades have witnessed the rapid development in tissue engineering, especially engineering with respect to vessel replacement [4], which provide a potential approach to cure the incompetent venous-valve. The first attempt in tissue-engineered venous valve was reported by Teebken [5], who implanted endothelial cells (ECs) and myofibroblasts derived from the vein wall of sheep into the acellular vein allograft, and then sutured it to the external jugular vein. The inspiring results were that the implanted tissue engineered venous valve functioned normally within first one month. However, small thromboses formed at the vascular suture site and venous sinus six weeks after transplantation. To avoid thrombus formation after transplantation, researchers took some measures to coat the inner surface of intima with

*Address correspondence to this author at the Second Military Medical University, Director of Institute of Biomedical Engineering, SMMU, Shanghai 200433, P. R. China; Tel: +86-021-81870949; Fax: +86-02181870949; E-mail: chuansen@yahoo.com

${ }^{\dagger}$ These authors contributed equally to this work. heparin or polyethylene oxide or endothelial cells. However, these measures were in failure.

Taking into account cells harvest and cells immunogenicity, the bone marrow-derived cells (BMCs) have been considered as a resource of differentiate into endothelial-like cells and smooth muscle-like cells [6]. Furthermore, the bone marrow-derived mononuclear cells (BMMNCs) contributed to tissue regeneration and improved stent endothelialization in vivo for tissue engineered blood vessels [7]. Instead of endothelial progenitor cells (EPC) to endothelial cells, the complex of matrix and cells maintained open for 130 days in an ovine tissue engineered blood vessel. These findings suggest that EPC may be preferred to endothelial cells as a cell resource to construct tissue-engineered blood vessels.

Based on previous studies [8,9], multipotent adult progenitor cells (MAPC) and EPC were harvested in the present study from bone marrow of beagle dogs, whose vein structure is similar to that of humans. These two progenitor cells were seeded into decellularized homologous venous conduit containing valve to construct the tissue-engineered venous valve. The complex morphology of matrix and cells, distribution and differentiation of these two progenitors were analyzed. Our study will provide an experimental basis for future in vivo tests of tissue-engineered venous valves.

\section{MATERIALS AND METHODS}

\section{Animals}

Adult beagle dogs, $(10-12 \mathrm{~kg})$ were obtained from the Animal Center at Second Military Medical University, 
China. All animals received care in compliance with the Guide for the Care and Use of Laboratory Animals, prepared by the Institute of Laboratory Animal Resources, National Research Council. All animals were anaesthetized with 30 $\mathrm{mg} / \mathrm{kg}$ pentobarbital. When necessary, the dose was increased by $3 \mathrm{mg} / \mathrm{kg}$.

\section{Generating Decellularised Allogeneic Scaffold}

Valve-bearing segments of canine femoral vein were confirmed as competent by the manual of operations [10], explanted, and immediately stored in phosphate-buffered saline (PBS; Sigma) at $4{ }^{\circ} \mathrm{C}$. Following this step, the vessels were decellularised using solution containing $0.5 \%$ Triton100 (AMRESCO, USA) and $0.05 \% \mathrm{NH}_{4} \mathrm{OH}$ with continuous shaking at $4^{\circ} \mathrm{C}$ for 3 days. They were then incubated in 20 $\mathrm{ml}$ of $1 \mathrm{M}$ sodium chloride solution with continuous shaking at $37{ }^{\circ} \mathrm{C}$ for $2 \mathrm{~h}$. This step was followed by incubation with $20 \mathrm{ml} 4 \%$ sodium deoxycholate (Sigma) at $4{ }^{\circ} \mathrm{C}$ for $60 \mathrm{~min}$. Decellularised vessels were then washed for $18 \mathrm{~h}$ and subsequently stored in PBS at $4{ }^{\circ} \mathrm{C}$.

\section{MAPC Isolation, Expansion, Separation and Charac- teristics}

MAPC were isolated and cultured as described by Breyer [11]. The MAPC selection medium contained $60 \%$ low glucose Dulbecco's Modified Eagle Medium (DMEM; Gibco BRL, Carlsbad, CA, USA), 40\% MCDB-201 (Sigma), $1 \times$ insulin-transferrin-selenium (ITS; Sigma), $1 \times$ linoleic acid bovine serum albumin (LA-BSA; Sigma), $10^{-9} \mathrm{M}$ dexamethasone (Sigma), $10^{-4} \mathrm{M}$ ascorbic acid 3-phosphate (Sigma), 100 units $/ \mathrm{mL}$ of penicillin, 1000 units $/ \mathrm{mL}$ of streptomycin (Gibco), 2\% fetal bovine serum (FBS; Hyclone, Logan, UT, USA), $10 \mathrm{ng} / \mathrm{mL}$ recombinant human platelet-derived growth factor (rhPDGF-BB; R\&D Systems, Minneapolis, MN, USA), $10 \mathrm{ng} / \mathrm{mL}$ recombinant human epidermal growth factor (rhEGF; Sigma), and 1000 units $/ \mathrm{mL}$ mouse leukemia inhibitory factor (Chemicon, Temecula, CA, USA). On the third passage, MAPC were sorted by magnetic Microbead separation with antibody against CD45 (from Miltenyi, Germany). Finally, the cells were placed in a $25 \mathrm{~cm}^{2}$ flask. After selection with magnetic beads, the cells were transferred to a culture flask or culture cluster (Corning). Upon reaching confluence, the cells were detached and identified by flow cytometry (De Novo Software, Inc., Ontario, Canada) using FITC labeling rabbit anti human SSEA-1 monoclonal antibody (Santa Cruz, USA). Then, the cells were detached and characterized by immunocytochemical staining using rabbit anti human SSEA-1 monoclonal antibody (Santa Cruz, USA) and rat anti human CD13 monoclonal antibody (Santa Cruz, USA).

\section{EPC Isolation, Expansion, Separation and Charac- teristics}

EPC were isolated and cultured as described by $\mathrm{Wu}$ [12]. The EPC selection medium consisted of 100 units $/ \mathrm{mL}$ of penicillin and 1000 units $/ \mathrm{mL}$ of streptomycin (Gibco) in endothelial cells growth medium MYZ (EGM-MV2; Promocell); EGM-MV2 contained endothelial basal medium-2 and Single aliquots containing 5\% fetal bovine serum (FBS), vascular endothelial growth factor (VEGF), human fibroblast growth factor B, human epidermal growth factor, insulin-like growth factor-1, ascorbic acid, hydrocortisone, and GA-1000. Just prior to reaching confluence, the cells were detached with $0.05 \%$ trypsin (Biochrom) and $0.02 \%$ EDTA (Sigma) in PBS without $\mathrm{Ca}^{+2}$ and $\mathrm{Mg}^{+2}$, then subcultured in $175 \mathrm{~cm}^{2}$ flasks (Corning). On the third passage, EPC were sorted by magnetic Microbead separation with antibody against CD133 (from Miltenyi, Germany). Finally, the cells were placed in a $25 \mathrm{~cm}^{2}$ flask. After selection with magnetic beads, the cells were transferred to a culture flask or culture cluster (Corning). Upon reaching confluence, the cells were detached and identified by flow cytometry (De Novo Software, Inc., Ontario, Canada) using PE labelling rabbit anti human CD133 monoclonal anti-body (Sigma, USA). Then, the cells were detached and characterized by immunocytochemical staining using rabbit anti human CD133 monoclonal antibody (Sigma, USA) and rat anti human CD14 monoclonal antibody (Sigma, USA). In summary, the references for each marker of MAPC and EPC were displayed in Table $\mathbf{1 .}$

Table 1. References for each Marker of MAPC and EPC

\begin{tabular}{|c|c|c|}
\hline $\begin{array}{l}\text { Cell } \\
\text { Type }\end{array}$ & Phenotype & References \\
\hline MAPC & $\begin{array}{l}\text { CD45, }{ }^{\circ} \text { MHC-II', CD } 344^{-}, \mathrm{OCT}_{-} 4^{+}, \\
\text {SSEA- }{ }^{+} .\end{array}$ & $\begin{array}{l}\text { 1.April Breyer, } \\
\text { Nima } \\
\text { Estharabadi, et al. } \\
\text { Multipotent adult } \\
\text { progenitor cell } \\
\text { isolation and culture } \\
\text { procedures. } \\
\text { Experimental } \\
\text { Hematology, } 34 \\
\text { (2006): } 1596-1601 \text {. }\end{array}$ \\
\hline EPC & 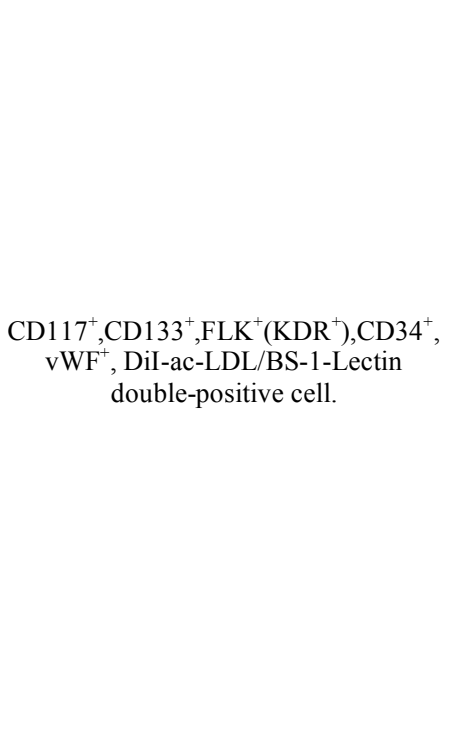 & $\begin{array}{l}\text { 1.Wei Zhang, } \\
\text { Guoping Zhang, et } \\
\text { al. Characteristics of } \\
\text { bone marrow- } \\
\text { derived endothelial } \\
\text { progenitor cells in } \\
\text { aged mice. } \\
\text { Biochemical and } \\
\text { Biophysical } \\
\text { Research } \\
\text { Communications, } \\
348 \text { (2006): 1018- } \\
\text { 1023. } \\
\text { 2. Mihail Hristov, } \\
\text { Wolfgang Erl, Peter } \\
\text { C. Weber. } \\
\text { Endothelial } \\
\text { Progenitor Cells } \\
\text { Isolation and } \\
\text { Characterization. } \\
\text { Trends Cardiovasc } \\
\text { Med, 2003; 13: 201- } \\
\text { 206. }\end{array}$ \\
\hline
\end{tabular}

\section{RT-PCR}

Total RNA was extracted using TRIzol (Invitrogen) [13]. Expression of OCT-4 and SM-MHC for MAPC and Expression of VE-cadherin, KDR, eNOS for EPC were determined by RT-PCR [14]. After the total RNA was extracted using purescript RNA isolation kit, the RT-PCR was performed in 
$25 \mu 1$ mixture and the PCR programs were described in Table 2.

Table 2. The Sense Primer, Antisense Primer and Annealing for OCT-4, SM-MHC, GAPDH, VE-Cadherin, KDR, Enos, GAPDH

\begin{tabular}{|c|c|c|c|c|}
\hline $\begin{array}{l}\text { Cell } \\
\text { Type }\end{array}$ & $\begin{array}{l}\text { Gene } \\
\text { Type }\end{array}$ & Sense Primer & $\begin{array}{l}\text { Antisense } \\
\text { Primer }\end{array}$ & Annealing \\
\hline \multirow{3}{*}{ MAPC } & OCT-4 & $\begin{array}{c}5^{\prime} \text {-GCG AAC } \\
\text { AAG TAT TGA } \\
\text { GA A CCG-3' }\end{array}$ & $\begin{array}{l}5^{\prime} \text {-GGG ACT } \\
\text { GAG GAG TAG } \\
\text { AGC GTA G-3' }\end{array}$ & $56.5^{\circ} \mathrm{C}$ \\
\hline & $\begin{array}{l}\text { SM- } \\
\text { MHC }\end{array}$ & $\begin{array}{c}\text { 5'-CTG CGG } \\
\text { CAA GTA } \\
\text { GGA-3' }\end{array}$ & $\begin{array}{c}\text { 5'-ATC TGC } \\
\text { GTT GGT GT- } \\
3 \text { ' }\end{array}$ & $49^{\circ} \mathrm{C}$ \\
\hline & GAPDH & $\begin{array}{c}\text { 5'-CAA GGC } \\
\text { TGT GGG CAA } \\
\text { GGT-3' }\end{array}$ & $\begin{array}{c}\text { 5'-CGA AGG } \\
\text { TGG AAGAGT } \\
\text { GGG T-3' }\end{array}$ & $55.3^{\circ} \mathrm{C}$ \\
\hline \multirow{4}{*}{ EPC } & $\begin{array}{l}\text { VE- } \\
\text { cadherin }\end{array}$ & $\begin{array}{c}5^{\prime}-\text {-CCT TGC } \\
\text { TGC TCT ACC } \\
\text { TCC-3' }\end{array}$ & $\begin{array}{c}5^{\prime} \text {-AAA TGC } \\
\text { TTT CTC CGC } \\
\text { TCT-3' }\end{array}$ & $53.7^{\circ} \mathrm{C}$ \\
\hline & KDR & $\begin{array}{c}5^{\prime}-\mathrm{CAT} \\
\text { GATCAG CTA } \\
\text { TGC TGG CAT } \\
\text { GGT C-3' }\end{array}$ & $\begin{array}{c}5^{\prime}-\mathrm{GGC} \text { GGG } \\
\text { ACA TTC ACA } \\
\text { A-3' }\end{array}$ & $51.8^{\circ} \mathrm{C}$ \\
\hline & eNOS & $\begin{array}{c}\text { 5'-CCC AGG } \\
\text { AGC TCA CAG } \\
\text { CAC AGC } \\
\text { CTGT-3' }\end{array}$ & $\begin{array}{c}5^{\prime} \text {-TTG AAC } \\
\text { AGC GGT GGA } \\
\text { GGA-3' }\end{array}$ & $54.7^{\circ} \mathrm{C}$ \\
\hline & GAPDH & $\begin{array}{l}\text { 5'-GCA TTT } \\
\text { GGT CGT } \\
\text { ATTGG-3' }\end{array}$ & $\begin{array}{c}5^{\prime} \text {-GGA TCT } \\
\text { CGC TCC TGG } \\
\text { AAG-3' }\end{array}$ & $52.5^{\circ} \mathrm{C}$ \\
\hline
\end{tabular}

\section{Tissue-Engineered Venous-Valve Construction in Vitro}

Decellularized canine vein scaffolds $(3 \mathrm{~mm}$ in diameter and $30 \mathrm{~mm}$ in length) were used as vascular matrices (Fig. $\mathbf{1 A}, \mathrm{n}=12$ ). These scaffolds were soaked in PBS in petri dish for 1 week (Fig. 1B). The scaffold was removed and placed on the blood vessel rack (Fig. 1C) according to the blood flow direction (vein valve tip direction). A $2 \times 10^{6}$ MAPC cell suspension $(500 \mu \mathrm{l})$ was uniformly seeded into decellularized scaffolds by multipoint injection (Fig. 1D). The blood vessels were placed into petri dishes with MAPC medium to culture for 1 week and turned over every day (Fig. 1E). Afterwards, one end of the blood vessel was fastened using 4-0 sutures (Fig. 1F) and $500 \mu 12 \times 10^{6}$ EPC cell suspension was injected into the blood vessel along the blood flow direction. The other end was fastened and the blood vessels were placed into petri dish with MAPC medium to culture for 1 week, being turned over every day. One end of the blood vessel was then cut and $500 \mu 12 \times 10^{6}$ EPC was injected into the vascular lumina in the direction opposite of blood flow. Both ends were fastened and the blood vessels were placed into a petri dish with MAPC medium to culture for 1 week and turned every day. Finally, the constructed blood vessel was taken out of the petri dish for characterization. All the above operations were carried out under sterile conditions.

\section{Scanning Electron Microscopy Observation}

The constructed TE venous valves were fixed with $1 \%$ $(\mathrm{v} / \mathrm{v})$ buffered glutaraldehyde for 30 minutes followed by $0.1 \%(\mathrm{v} / \mathrm{v})$ buffered formaldehyde for 24 hours. The valves were then dehydrated with a gradient ethanol series and

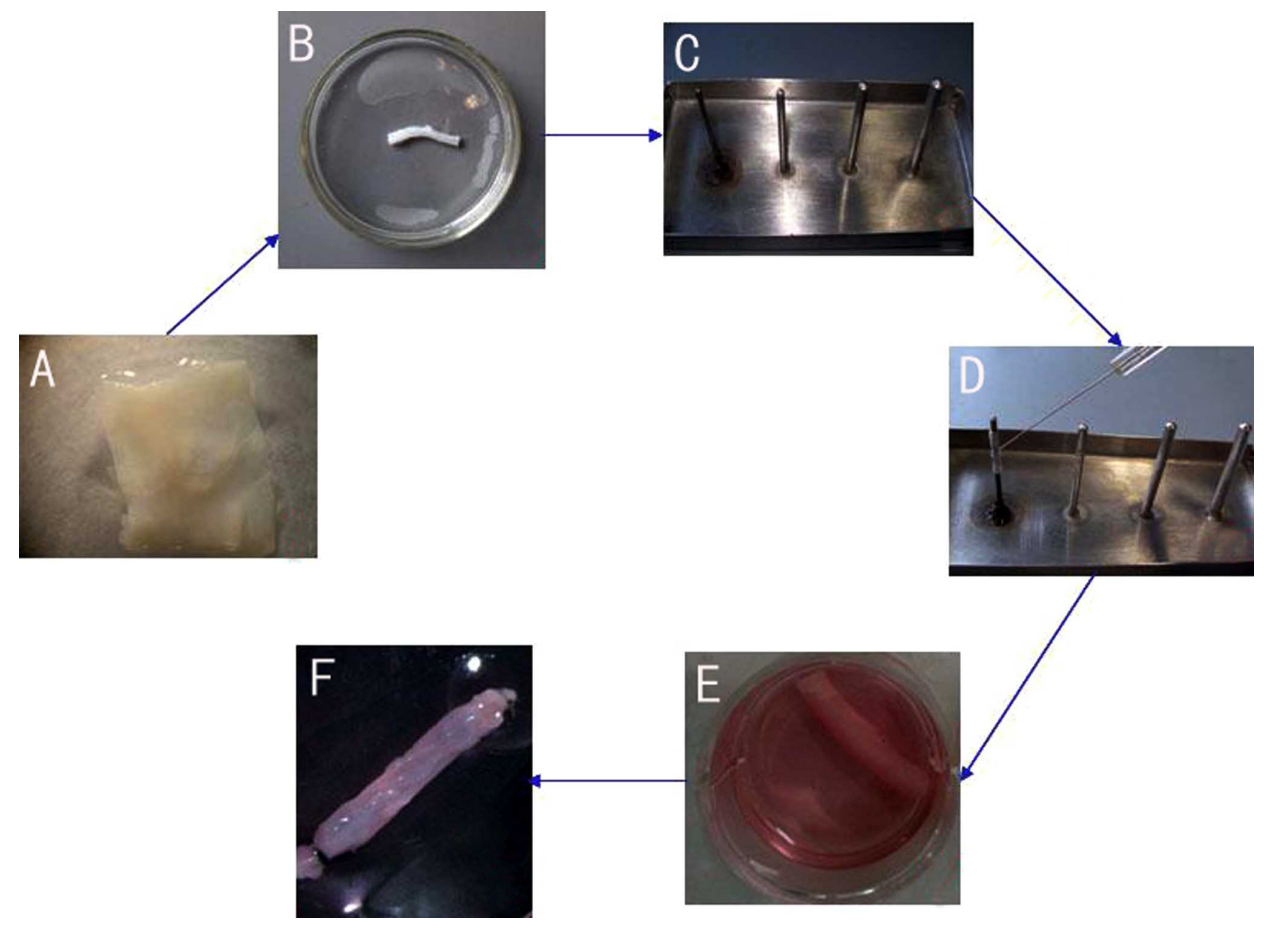

Fig. (1). Construction of tissue-engineered venous valve in vitro. A) A gross view of canine acellular vein scaffold containing valve (length = $30 \mathrm{~mm}$, ID = 3MM). The scale is in centimeters. B) Scaffold is soaked in PBS for one week. C) Blood rack (from left to right, ID = 2, 3, 4, and $5 \mathrm{~mm}$, respectively). D) Scaffold is placed on the rack (ID =2mm), MAPC and EPC are injected using a microinjector. E) Scaffold cultured in medium after being implanted with MAPC and EPC. F) One end of scaffold was fastened using 4-0 suture and EPC were injected into the inner luminal. 
dried. The dried specimens were mounted on an aluminum stub and sputter-coated with gold. A scanning electron microscope (JSM-6330F; JEOL, Tokyo, Japan) was used to image the specimens [15].

\section{Biomechanical Testing}

Undisposed normal canine femoral veins were used as a physical control group $(C, n=5)$. Acellular scaffolds were used for the acellular group $(\mathrm{A}, \mathrm{n}=5)$ and TE venous valves were used in the experimental group (TEVV, $\mathrm{n}=5)$. A universal electronic strength apparatus (Instron model 1122; Instron, UK) was used to test the reversion rate of elasticity and the maximum breaking strength of specimens and calculate the average value of each group. Prior to testing, each specimen was preconditioned 8 times with a $7.84 \mathrm{~N}$ tensile force.

\section{Cell Labeling and Tracking Observation}

MAPC and EPC were labeled by Hoechst or PKH26 (PKH26 Red Fluorescent Cell Linker Kit, Sigma), respectively, before transplantation. Labeling was carried out according to previously described protocols $[16,17]$. After being cultured in vitro, the TE venous valves were removed and wrapped with aluminum-foil and put into the ultra-low temperature refrigerator or liquid nitrogen for $2 \mathrm{~min}$ to freeze. After freezing, the cells specimens were embedded by OCT and sectioned into 5um slices on a microtome (Leica model CM 1950; Leica, Germany). The growth of the cells in the scaffold was determined by observation with a fluorescent microscope.

\section{HE Staining and Immunohistochemistry Detection}

Acellular scaffolds, TE venous valves, and normal canine veins were fixed in $10 \%$ formaldehyde followed by ethanol gradient dehydration. Specimens were embedded in paraffin and divided into $5 \mu \mathrm{m}$ sections, and HE staining was used to detect the distribution of cells in the scaffold. Masson staining was used to evaluate collagen fiber and elastic fiber structure; Immunofluorescence techniques were used to detect the expression of vWF (Rabbit Polyclonal Antibody, Thermo), VEGF (Rabbit Polyclonal Antibody, Thermo), CD133 (Rabbit Polyclonal Antibody, Thermo), Desmin (Mouse monoclonal Antibody, Abcam), and $\alpha$-actin (Monoclonal Anti- $\alpha$ Smooth Muscle Actin, Sigma) in tissue. Immunofluorescence procedure was performed by the manual of operation. A goat anti-mouse or goat anti-rabbit served as secondary antibody (DAKO). Specimens were viewed under fluorescence microscope. Corresponding negative and positive control staining were performed for each antibody.

\section{Statistical Analysis}

Data were expressed as the mean \pm SD. Statistical analysis was performed by unpaired Student's $t$-tests using SPSS 10.0 software. A value of $P<0.05$ was considered to be statistically significant.

\section{RESULTS}

\section{Acellular Scaffold Morphology and Structure}

Canine allogenic veins containing valves as acellular scaffold are shown in Fig. (2A). The absence of cell nuclei and intracellular components in the acellular matrix before re-seeding was demonstrated by HE staining of 10 specimens (Fig. 2B). Scanning electron microscopy showed that fiber connections of the acellular scaffold were continual, there was no fracture, and the scaffold formed a natural skeleton (Fig. 2C). Masson staining revealed that elastic fibers and collagen fibers were well preserved with a cross arrangement (Fig. 2D, 2E, 2F).
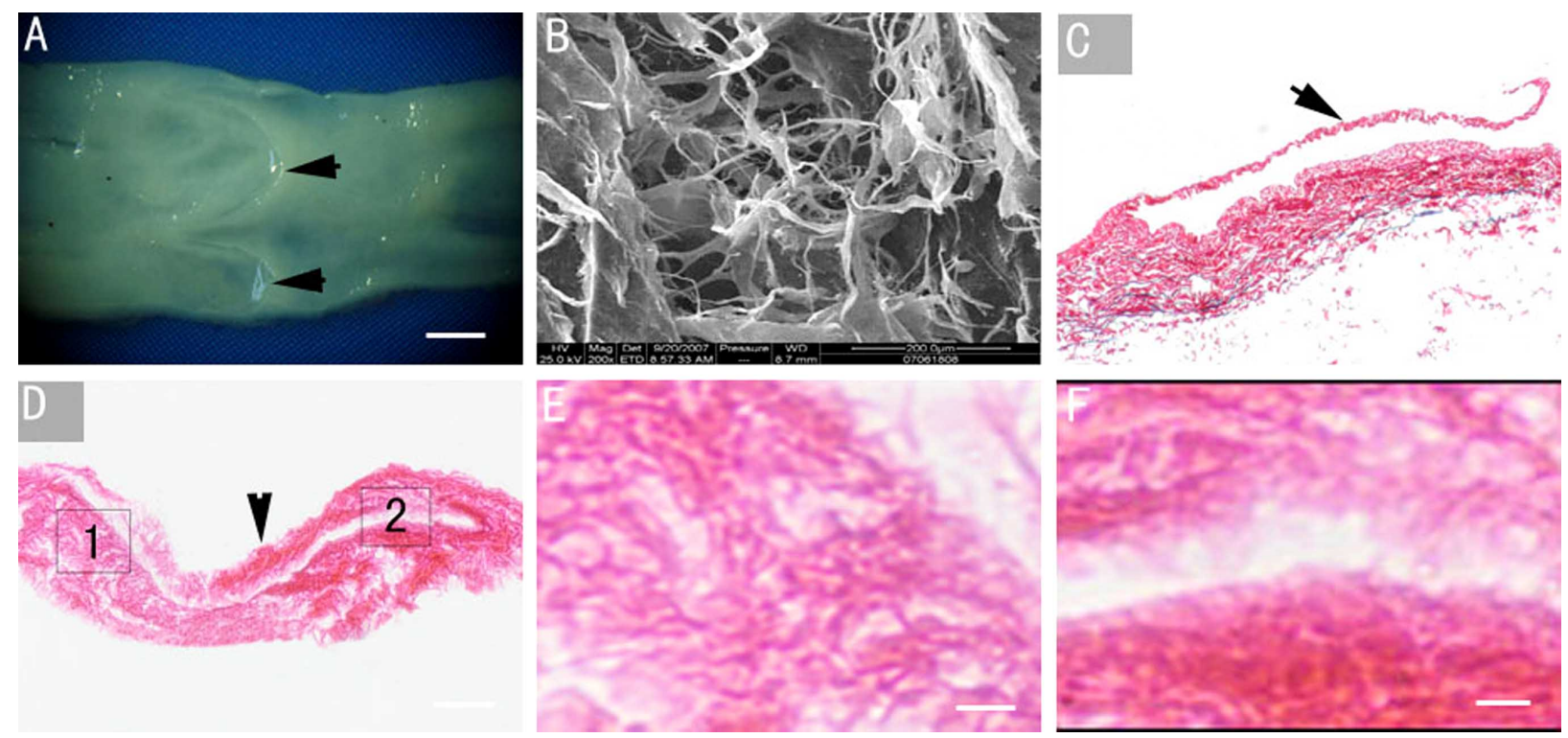

Fig. (2). Characterization of the acellular scaffold. A) Gross view of the acellular scaffold B) Scanning electron micrograph of the crosssection of the matrix. C) Masson staining shows that elastic fibers and collagen fibers were well preserved; elastic fibers are green, collagen fibers are pink. D) HE staining showing complete removal of cellular components from canine vein containing valve. E) Location magnification of circle 1of image D. F) Location magnification of circle 2of image D. (Black arrow points to the venous valve in the figure). Scale bars, A,C,D, $20 \mu \mathrm{m}$; B,200nm; E,F, $5 \mu \mathrm{m}$. 


\section{Cells Growth Features and Properties}

Canine bone-marrow-derived cells grew well during primary culture and subculture. After sorting, the cells were highly homogeneous and displayed rapid proliferation capacity. MAPC primary cells grew radiatly surround the central cells on day 7 (Fig. 3A). After passaging, cells had clone-like growth, polygonal morphology, and complete confluence in 3-5 days (Fig. 3B). On day 7, EPC primary cells demonstrated colony-like growth and the cell morphology was that of a short spindle (Fig. 3C). EPC were completely confluent in 3-5 days after passage and were arranged in a cluster on day 5 (Fig. 3D). After being sorted by microbeads, cells were determined as MAPC and EPC through immunocytochemistry (Fig. 3E-H), flow cytometer (Fig. 3I, J), and RT-PCR (Fig. 3K, L).

Tissue-Engineered Venous-Valve Morphology and Biomechanical Property

After cells were seeded into scaffolds and reconstruction was completed in vitro, the TE blood vessels (Fig. 4B)
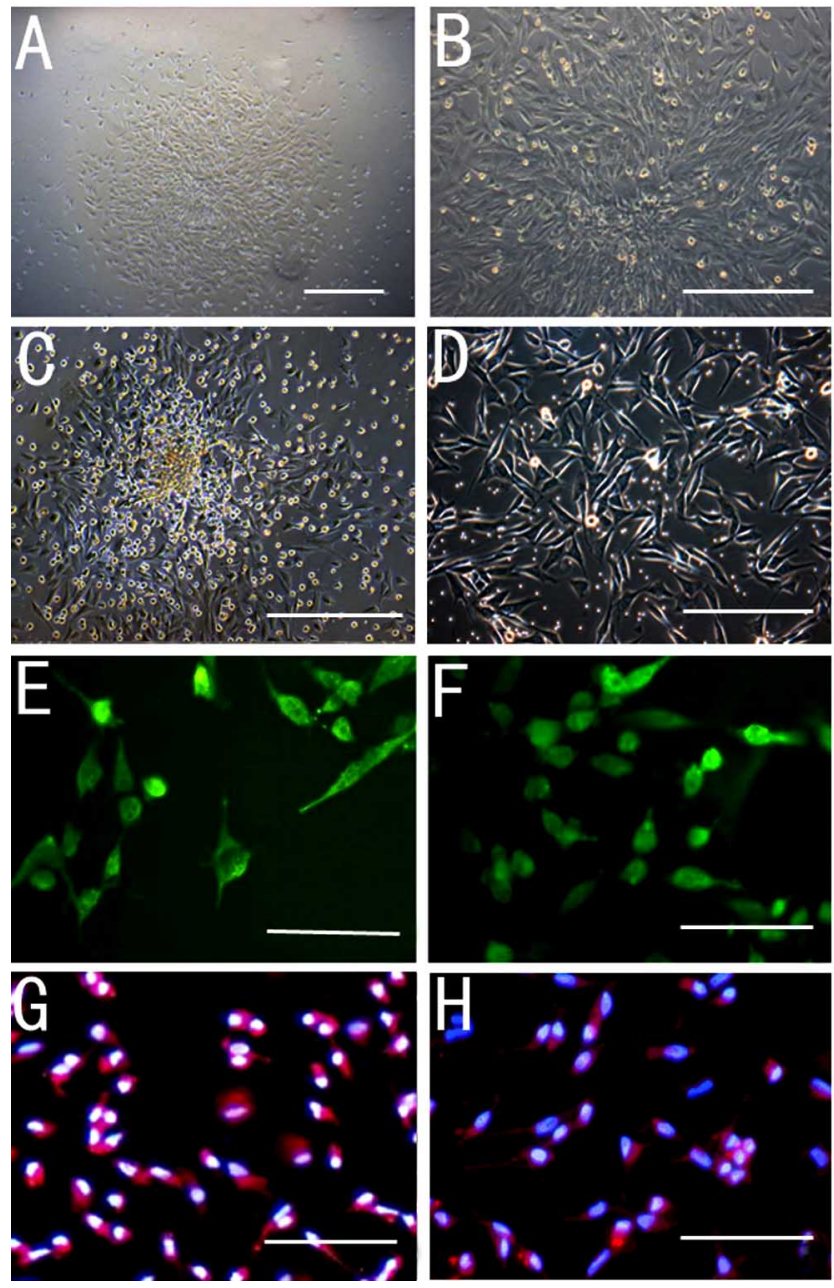

Fig. (3). Characterization of cultured bone-marrow-derived cells. A) MAPC primary culture on day 7. B) MAPC $2^{\text {nd }}$ passage on 5 day. C) EPC primary culture on day 7. D) EPC $2^{\text {nd }}$ passage on day 5. Immunocytochemistry: E) MAPC, CD $13^{+}$; F) MAPC, SSEA-1 $1^{+}$; G) EPC, CD $133^{+}$; H) EPC, CD14 ${ }^{+}$FACS analysis: I) left, MAPC SSEA-1 expression rate $31.47 \%$; RT, $2^{\text {nd }}$ antibody as MAPC control, expression rate $0.09 \%$; J) left, EPC CD133 expression rate $13.95 \%$; RT, $2^{\text {nd }}$ antibody as EPC control, expression rate $1.79 \%$. Agarose gel electrophoresis of RT-PCR products: K) 1, Marker; 2, MAPC expressed OCT-4 and SM-MHC; L) 1, Marker; 2, EPC expressed VEcadherin, KDR and Enos. Scale bars, A-D, $100 \mu \mathrm{m} ; \mathrm{E}-\mathrm{F}, 50 \mu \mathrm{m}$. containing venous valves had no external morphological differences compared with natural blood vessels (Fig. 4A, 4C). Biomechanical testing showed that the Control group had the greatest recovery rate and maximum breaking strength, followed by the TEVV group and lastly the A group. Despite this trend, there was no significant differences $(\mathrm{P}>0.05)$ between TEVV group and control group, although the TEVV group was significantly greater than the A group $(\mathrm{P}<0.05)$ (Fig. 4D, E).

\section{Relative Molecular Expression, Cells Distribution and} Fiber Structure in the Tissue-Engineered Venous-Valve

Immunohistochemistry showed that desmin, $\alpha$-actin, vWF, VEGF, and CD133 were positively expressed on both surfaces of the valve and in the vascular wall of TE venous valves (Fig. 5A-E). HE staining showed that TE venousvalve cell distribution (Fig. 5F) was similar to normal blood vessels (Fig. 5G), and that the cells formed a cell monolayer on the inner surface of the vessel wall and both sides of the valve. Masson staining showed that the elastic fibers and
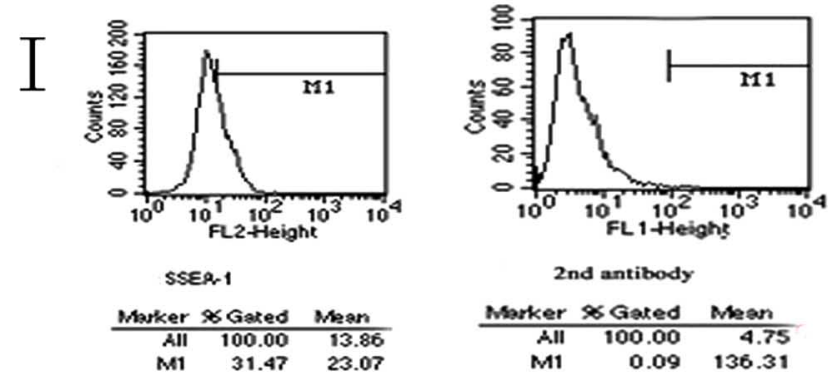

$\mathrm{J}$
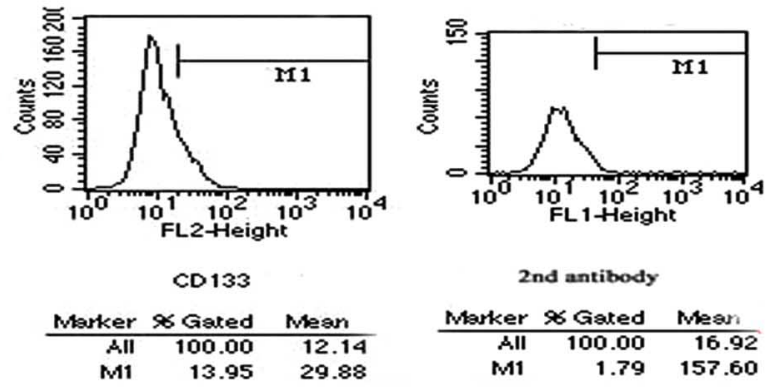

K

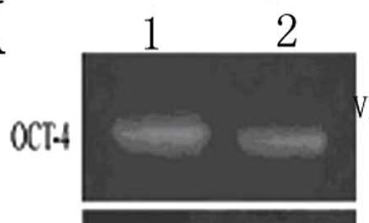

SHAMHC
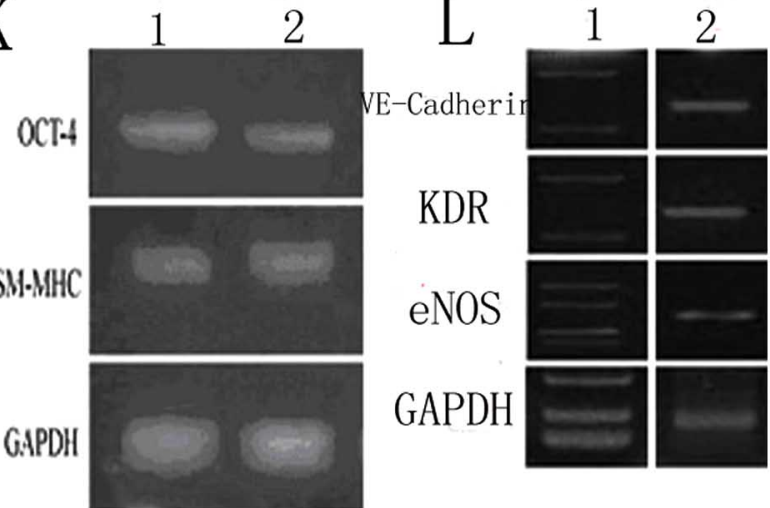

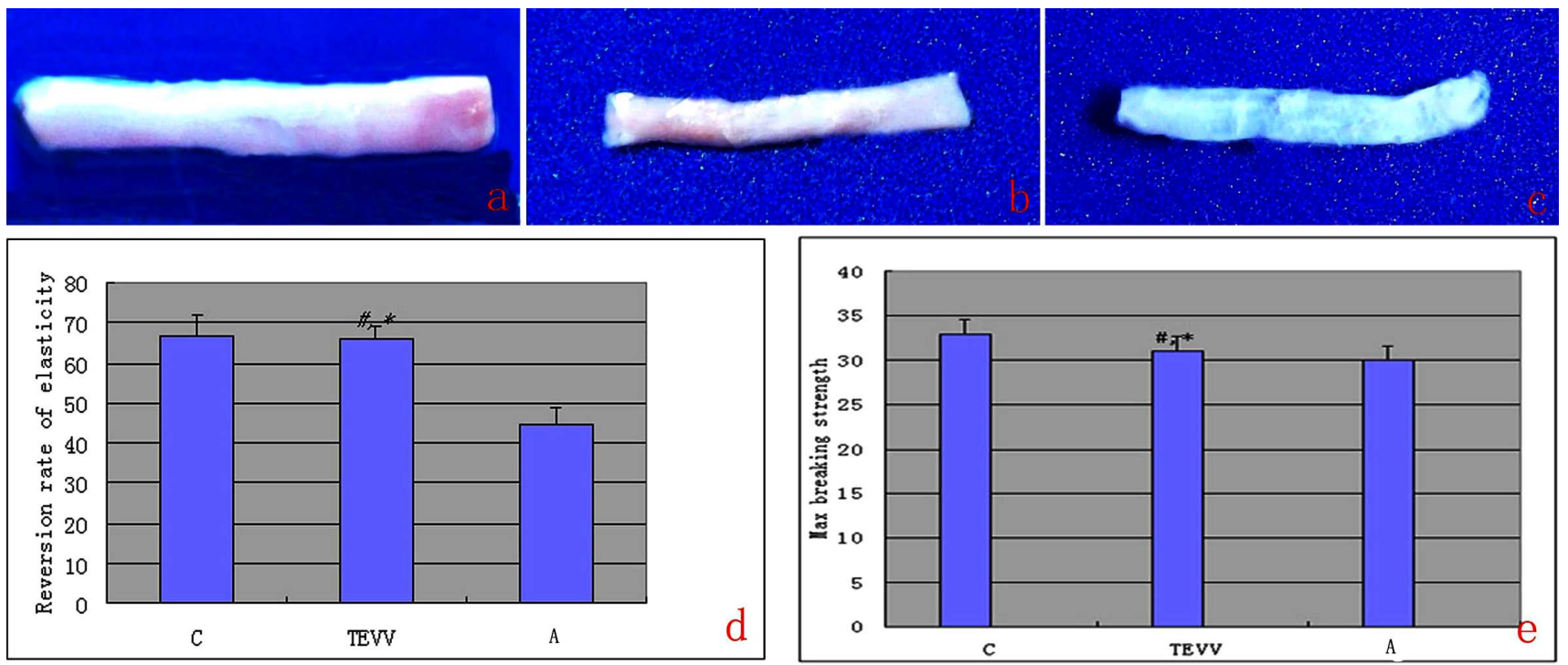

Fig. (4). Vascular biomechanicals testing. A) Natural canine blood vessel. B) Tissue-engineered vein containing venous valve. C) Acellular allogenic vein scaffolds. D) Reversion rate of elasticity differences among every group, ${ }^{\#} \mathrm{P}>0.05, \mathrm{TEVV} v s . \mathrm{C} ;{ }^{*} \mathrm{P}<0.05, \mathrm{TEVV}$ vs. A. E) Max breaking strength difference of every group, ${ }^{*} \mathrm{P}>0.05$, TEVV $v s . \mathrm{C} ;{ }^{*} \mathrm{P}<0.05$, TEVV $v s . \mathrm{A}$.
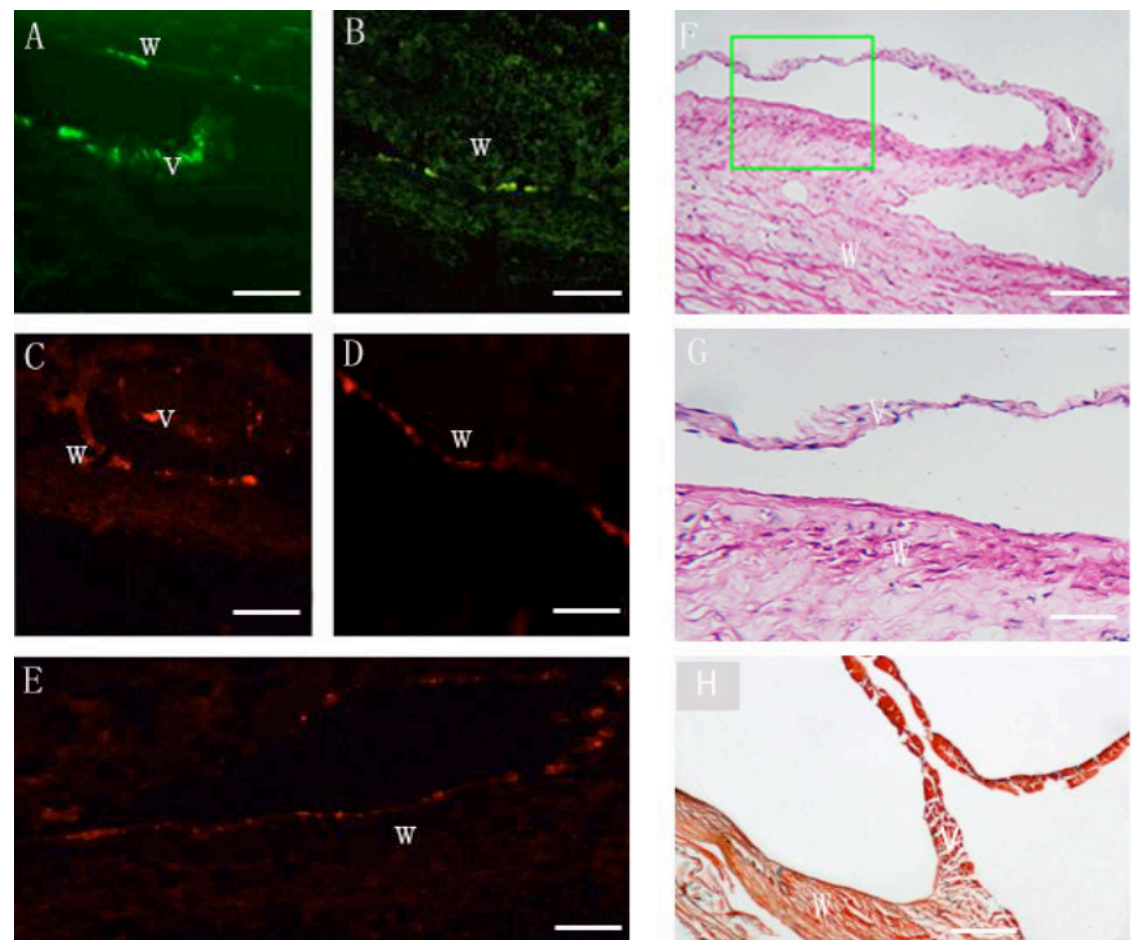

Fig. (5). HE staining and immunohistochemical characterization of TE venous valve paraffin section. A) Desmin. B) $\alpha$-actin. C) vWF. D) VEGF. E) CD133. F) TE venous valve. G) Location magnification of green circle of image F. H) Masson staining of TE venous valve; green indicates elastic fibers, pink indicates collagen fibers. (Letter V indicated vein valves, letter W indicated vein wall). Scale bars, A-F,H, $20 \mu \mathrm{m} ; \mathrm{G}, 5 \mu \mathrm{m}$.

collagen fibers were regularly arranged to form a cross after culturing in vitro (Fig. 5H). There was no significant difference between the cultured or the unicellular, natural veinfiber arrangement (Fig. 2D).

\section{Cells Tracking of Tissue-Engineered Venous Valve}

Hoechst and PKH26 were used to successfully label MAPC and EPC, respectively (Fig. 6A, B). After construction of the in vitro culture, the labeled cells grew well in the valve and migrated to the internal layer of the valve as evidenced by the fluorescent microscopy of the frozen sections (Fig. 6C-F).

\section{DISCUSSION}

Previous studies suggested that TE venous valves were not suitable for transplantation into humans. In our study, we successfully cultured and identified canine bone-marrow- 

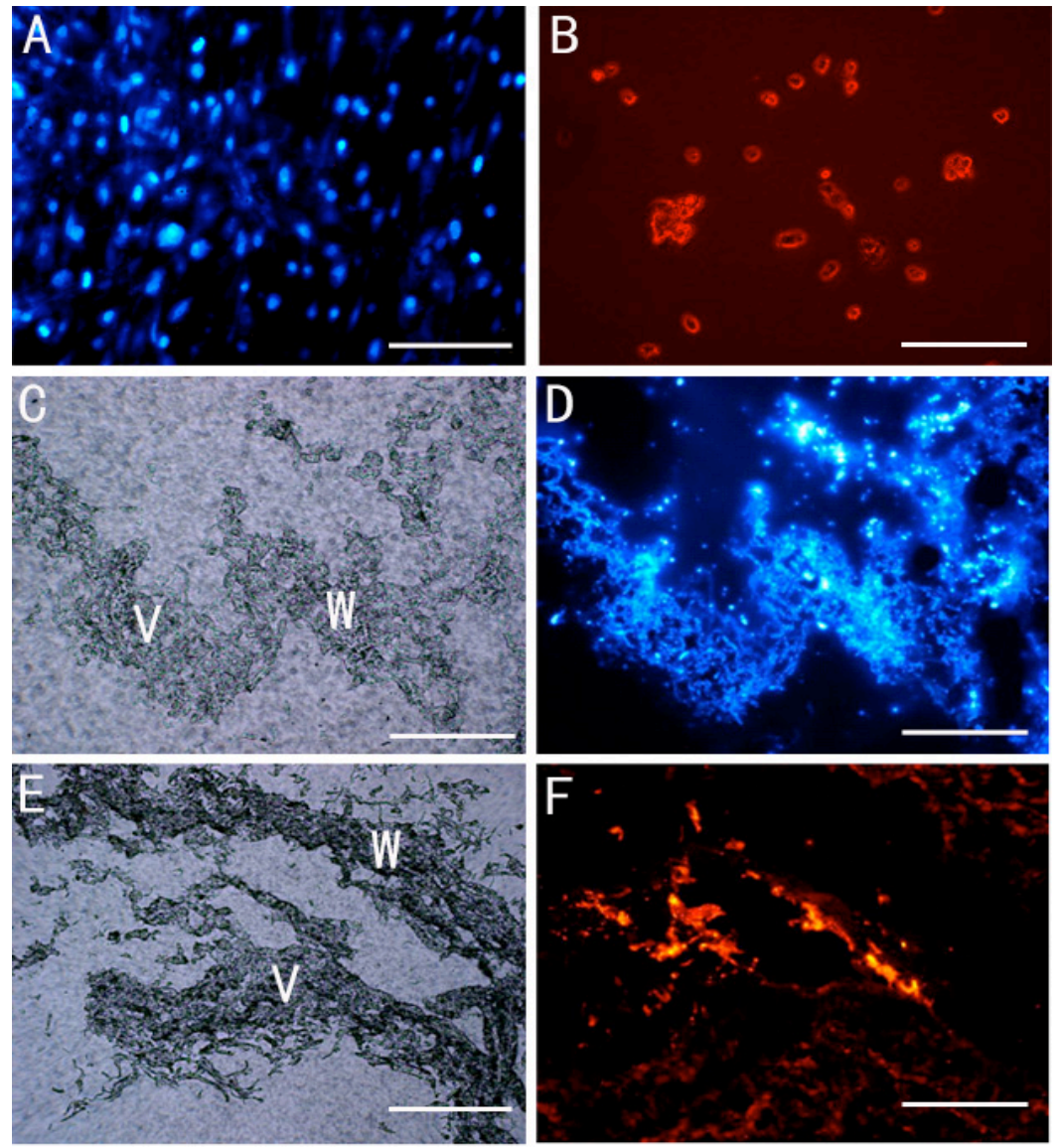

Fig. (6). Cell labeling and tracking. A) MAPC nuclei display blue Hoechst label. B) EPC cytoplasm displays red PKH26 label. C), E) venous valve under phase contrast microscope. D), F) distribution of MAPC and EPC in the same visual field, respectively. Additional graph labels: vein wall (W), vein valve (v). Scale bars, A-B, $50 \mu \mathrm{m}$; C-F, $100 \mu \mathrm{m}$.

derived MAPC and EPC for use as seeding cells, and employed canine allogeneic acellular matrix materials as scaffolds to construct TE venous valves in vitro. The reconstruction method was designed to ensure that the basic structure of the TE venous valves was similar to natural valves.

Compared to mature cells, MAPC and EPC have strong proliferation and multi-directional differentiation potential. They can differentiate into a variety of cells, which is essential for vascular venous-valve reconstruction. Additionally, some proteins which these cells secreted can optimize the vascular wall structure. Compared with artificial polymerized materials, allogeneic acellular vascular scaffolds not only retained natural blood vessel extracellular matrix which is necessary to provide complex physical structure for threedimensional reconstruction, but also maintained mechanical stability $[18,19]$. Our study results strongly suggest that acellular scaffolds treated with the non-ionic detergent (Triton X-100) provide a good substrate structure for cell growth. If subsequently treated using DNase and RNase, the acellular scaffold will not produce an immune response in the body [20] because cellular components are completely removed from the system (Fig. 2B). Biomechanical test results showed using natural vascular tissue as a scaffold, combined with cells, results in specimens with similar structure to natural blood vessels.
Vascular wall endothelialization is a critical step during construction of TE blood vessels [211. In our study, HE staining and immunohistochemistry revealed that cells grew and formed a cellular monolayer in the vascular wall and on both sides of venous valves. Some researchers have found that bone marrow-derived cells (BMCs) can be induced to differentiate into smooth muscle-like cells and endotheliallike cells $[22,23]$, which is also consistent with our study results; thus, BMCs can act as another cell resource for TE blood vessels.

It should be noted that the construction of the TE venous valves was carried out under static conditions, and the effects of shear stress of blood flow on the structure is not known. The ability of TE venous valves to maintain blood flow must to be further investigated in next plans.

Several potential advantages are evident in our approach to venous-valve construction. Bone-marrow-derived MAPC and EPC culture methods are simple and the technology is mature. Aspiration of bone marrow can reduce patient's pain and suffering compare to traditional peripheral blood vessel biopsies. Bone marrow can be recycled and will not be harmful to patients. Auto-bone-marrow-derived cells can reduce immune rejection response. On the basis of results from this study, the use of bone marrow-derived MAPC and EPC can serve as ideal cells for TE venous valves. 


\section{DISCLOSURE STATEMENT}

No competing financial interests to declare.

\section{ACKNOWLEDGEMENTS}

This work was supported by a grant from the National Natural Science Foundation (No. 30672045, China).

\section{REFERENCES}

Ruckley CV, Evans CJ, Allan PL, Lee AJ, Fowkes FG. Chronic venous insufficiency: clinical and duplex correlations. The Edinburgh Vein Study of venous disorders in the general population. J Vasc Surg 2002; 36(3): 520-5.

[2] Schoevaerdts JC, Staelens I. Programme for detecting chronic venous insufficiency in Belgium. Phlebology 2007; 22(4): 171-8

[3] Pavcnik D, Yin Q, Uchida B, et al. Percutaneous autologous venous valve transplantation: short-term feasibility study in an ovine model. J Vasc Surg 2007; 46(2): 338-45.

[4] Chlupác J, Filová E, Bacáková L. Blood vessel replacement: 50 years of development and tissue engineering paradigms in vascular surgery. Physiol Res 2009; 58 (Suppl 2): S119-39.

[5] Teebken OE, Puschmann C, Aper T, Haverich A, Mertsching H. Tissue-engineered bioprosthetic venous valve: a long-term study in sheep. Eur J Vasc Endovasc Surg 2003; 25(4): 305-12.

[6] Kashiwakura Y, Katoh Y, Tamayose K, et al. Isolation of bone marrow stromal cell-derived smooth muscle cells by a human SM22alpha promoter: in vitro differentiation of putative smooth muscle progenitor cells of bone marrow. Circulation 2003; 107(16): 2078-81.

[7] Reyes M, Dudek A, Jahagirdar B, et al. Origin of endothelial progenitors in human postnatal bone marrow. J Clin Invest 2002; 109(3): 337-46

[8] Jiang Y, Vaessen B, Lenvik T, et al. Multipotent progenitor cells can be isolated from postnatal murine bone marrow, muscle, and brain. Exp Hematol 2002; 30(8): 896-904.

[9] Asahara T, Murohara T, Sullivan A, et al. Isolation of putative progenitor endothelial cells for angiogenesis. Science 1997; 275(5302): 964-7.
[10] Dalsing MC, Lalka SG, Unthank JL, et al. Venous valvular insufficiency: influence of a single venous valve (native and experimental). J Vasc Surg 1991; 14(5): 576-87.

[11] Breyer A, Estharabadi N, Oki M, et al. Multipotent adult progenitor cell isolation and culture procedures. Exp Hematol 2006; 34(11): 1596-601.

[12] Wu Y, Zhang J, Gu Y, et al. Expansion of canine bone marrowderived endothelial progenitor cells and dynamic observation. Ann Vasc Surg 2006; 20(3): 387-94.

[13] Marina K. TRIzol for plasmid DNA isolation. Tech Tips Online 1997; 1: 76-7.

[14] Sun B, Wells J, Goldmuntz E, et al. A simplified, competitive RTPCR method for measuring rat IFN-gamma mRNA expression. J Immunol Methods 1996; 195(1-2): 139-48.

[15] Lloyd CM, Phillips AR, Cooper GJ, Dunbar PR. Three-colour fluorescence immunohistochemistry reveals the diversity of cells staining for macrophage markers in murine spleen and liver. J Immunol Methods 2008; 334(1-2): 70-81.

[16] Healey G, Veale MF, Sparrow RL. A fluorometric quantitative erythrophagocytosis assay using human THP-1 monocytic cells and PKH26-labelled red blood cells. J Immunol Methods 2007; 322(12): 50-6.

[17] Maes ML, Davidson LB, McDonagh PF, Ritter LS. Comparison of sample fixation and the use of LDS-751 or anti-CD45 for leukocyte identification in mouse whole blood for flow cytometry. J Immunol Methods 2007; 319(1-2): 79-86.

[18] Schmidt CE, Baier JM. Acellular vascular tissues: natural biomaterials for tissue repair and tissue engineering. Biomaterials 2000; 21(22): 2215-31.

[19] Teebken OE, Haverich A. Tissue engineering of small diameter vascular grafts. Eur J Vasc Endovasc Surg 2002; 23(6): 475-85.

[20] Kerdjoudj H, Boura C, Marchal L, et al. Decellularized umbilical artery treated with thin polyelectrolyte multilayer films: potential use in vascular engineering. Biomed Mater Eng 2006; 16(4 Suppl): S123-9.

[21] Shi Q, Rafii S, Wu MH, et al. Evidence for circulating bone marrow-derived endothelial cells. Blood 1998; 92(2): 362-7.

[22] Reyes M, Dudek A, Jahagirdar B, Koodie L, Marker PH, Verfaillie CM. Origin of endothelial progenitors in human postnatal bone marrow. J Clin Invest 2002; 109(3): 337-46

[23] Galmiche MC, Koteliansky VE, Brière J, Hervé P, Charbord P Stromal cells from human long-term marrow cultures are mesenchymal cells that differentiate following a vascular smooth muscle differentiation pathway. Blood 1993; 82(1): 66-76.

(C) Wen et al.; Licensee Bentham Open.

This is an open access article licensed under the terms of the Creative Commons Attribution Non-Commercial License (http: //creativecommons.org/licenses/by$\mathrm{nc} / 3.0 /$ ), which permits unrestricted, non-commercial use, distribution and reproduction in any medium, provided the work is properly cited. 